\title{
Caprine Semen Cryopreservation and the Factors Affecting it: An Overview
}

\section{Amit Sharma ${ }^{1^{*}}$ and Pankaj Sood ${ }^{2}$}

${ }^{1}$ Department of Veterinary Gynaecology and Obstetrics, CSK Himachal Pradesh Krishi Vishvavidyalya, Palampur- Himachal Pradesh 176062, India; ${ }^{2}$ Department of Veterinary Clinical Complex, CSK Himachal Pradesh Krishi Vishvavidyalya, Palampur- Himachal Pradesh 176062, India.



\section{Introduction}

$\mathrm{C}$ ryopreservation of cells and tissues has high importance in reproductive biotechnology for the preservation of gametes and embryos, implementation of gene banking and breeding programs of rare and endangered species but also for rare breeds of domestic animals. Sperm cryopreservation together with different assisted reproduction techniques (ART's) such as artificial insemination allows us to use the semen from valuable sires, the preservation of endangered species, to solve problems of male infertility and exchange of semen between subpopulations that may become geographically or biologically isolated (Watson and Holt, 2001; Andrabi and Maxwell, 2007). Smith and Polge (1950) did pioneering work in goat semen cryopreservation. Barker (1957) was the first to suggest that fertility of frozen-thawed goat semen was too low to be of practical value. Since then, different extenders and freezing procedures have been described in different animal species, especially in bull (Martin et al., 2004), goat (Jimenez-Rabadan et al., 2013; Konyali et al., 2013; Sharma, 2018; Sharma et al., 2020) and ram (Aisen et al., 2002; Munyai, 2012) to minimize detrimental effects of cryopreservation on sperm motility, viability, morphology (Gravance et al., 1997), plasma membrane (Parks and Graham, 1992), acrosome (Celeghini et al., 2008) and DNA (Yildiz et al., 2007) integrity.

The cryopreservation of mammalian sperm is an intricate process that involves which involves balancing many factors in order to obtain satisfactory results. To ensure even minimal success, not only 
proper diluent, sperm dilution rate, cooling rate and thawing rate are required, but also an intricate knowledge of the sperm physiology for the species is essential to maximize post-thaw recovery of sperm and consequently the fertility.

Sperm cryopreservation produces ultrastructural, biochemical and functional damage to the spermatozoa (Leboeuf et al., 2000) due to dramatic temperature changes, submission to osmotic and toxic stress derived from exposure to cryoprotectants and formation and dissolution of ice in the intracellular and extracellular environment (Medeiros et al., 2002). These effects would result finally in reduced motility, viability, impaired transport and fertility (Leboeuf et al., 2000).

Sperm preservation protocols differ between animal species, due to their inherent abilities to accommodate variations in semen extenders used in the cooling and freezing processes (Barbas and Mascarenhas, 2009). Bailey et al. (2000) proposed compositional differences of the sperm plasma membrane as reason for species variation of sperm cryosensitivity. Hiemstra et al. (2005) observed considerable differences in semen 'freezability' amongst breeds and between individual males of the same species (Hiemstra et al., 2005). In general, the spermatozoa of small ruminants are extremely sensitive to cryopreservation compared to other species (Purdy, 2006; Gangwar et al., 2016).

Semen cryopreservation is distinctly different from processing of cattle or buffalo semen and hence, remains a challenge because of the peculiarity observed in this species. The seminal plasma of goat semen contains Egg Yolk Coagulating enzymes, EYCE (phospholipase A2) and SBUIII from the secretions of the bulbourethral glands that interacts with the egg yolk and skimmed milk (one of essential and economical component of semen extender) thus producing toxic substances that affects sperm cells (Purdy, 2006: Gangwar et al., 2016) and reduces its freezing ability (Leboeuf et al., 2000: Purdy, 2006: Gangwar et al., 2016). It is presumed that EYCE and SBUIII is the same molecule (Leboeuf et al., 2000; Parkinson, 2009). The EYCE was identified as phospholipase A (Iritani and Nishikawa, 1963: Shipley et al., 2007) and SBUIII as a $55-60 \mathrm{kDa}$ glycoprotein lipase from the goat bulbourethral gland BUSgp60 (Pellicer-Rubio et al., 1997). EYCE acts as a catalyst which hydrolyzes egg yolk lecithin into fatty acids and lysolecithin (Iritani and Nishikawa, 1963: Shipley et al., 2007). This hydrolysis reaction causes the sperm membranes to be more fusogenic thereby inducing the acrosome reaction (Upreti et al., 1999; Purdy, 2006), and chromatin decondensation (Sawyer and Brown, 1995), both of which are toxic to the sperm. BUSgp60 lipase has structural homology to porcine pancreatic lipases (Carriere et al., 1994) and, similar to EYCE, BUSgp60 is responsible for hydrolysis of plasma membrane triglycerides and triglycerides in the skim milk that results result in fatty acid production (oleic acid) which is again toxic to sperm (Pellicer-Rubio et al., 1997; Pellicer-Rubio and Combarnous, 1998). Irrespective of mechanisms of action of either EYCE or BUSgp60, their activation in diluents is detrimental to the quality of the sperm cells during cryopreservation (Pellicer-Rubio et al., 1997; Pellicer-Rubio and Combarnous, 1998).

The conventional method of overcoming the harmful interactions of seminal plasma and egg yolk or milk proteins is to dilute the goat semen sample in a buffered diluent and then separate the seminal plasma from the sperm by centrifugation (Leboeuf et al., 2000: Purdy, 2006; Nuti, 2007; Tabarez et al., 2017; Narwade et al., 2017; Sharma, 2018; Sharma et al., 2018a, b; Sharma and Sood, 2019a, b). Nevertheless, another group of researchers observed that removal of seminal plasma may have a negative effect on sperm quality (Azeredo et al., 2001). Accordingly, there still exists a contradiction on whether to remove seminal plasma or not. Washing semen samples, however, is a time-consuming process that may damage cells if performed improperly but, if performed correctly, can be beneficial. Alternative diluents which minimize the sperm and lipase interactions have been proposed, including adding BUSgp60 lipase inhibitors, using lipid-free cow milk, a triglyceride-free diluent containing the milk protein casein, or using milk from species other than dairy cows where fatty acid and triacylglycerol structure differ so that the enzymatic reactions don't doesn't occur (Pellicer-Rubio and Combarnous, 1998; Purdy, 2006). Kundu et al. (2000, 2001, 2002) demonstrated the usage of egg yolk and milk-free media for goat semen cryopreservation.

Semen cryopreservation involves common steps to any protocol such as collection and extension of semen, addition of cryoprotectant, cooling above $0^{\circ} \mathrm{C}$, cooling below $0^{\circ} \mathrm{C}$, storage and thawing (Curry, 2007). 
Cryopreservation extender and cryoprotectants

Extender: The main purpose of a cryopreservation extender is to supply the sperm cells with source of energy, protect the cells from cold shock and maintain a conducive condusive environment for the spermatozoa to survive temporarily. In general, a goat sperm cryopreservation medium includes a non-penetrating cryoprotectant (milk or egg yolk), a penetrating cryoprotectant (glycerol, ethylene glycol, or dimethyl sulfoxide DMSO), a buffer (Tris or Test), one or more sugars (glucose, lactose, raffinose, saccharose, dextran or trehalose), salts (sodium citrate, citric acid) and antibiotics (penicillin, streptomycin) (Evans and Maxwell, 1987; Sharma, 2018). A nonfat dried skim milk diluent (Corteel, 1974) or a Trisglucose diluent (Salamon and Ritar, 1982; Beltran et al., 2013; Sharma, 2018; Sharma et al., 2020) are most commonly used for cryopreserving goat sperm. Various researchers suggested Tris-citric acid to be most satisfactory buffer for goat spermatozoa (Mishra et al., 2010; Sharma, 2018; Sharma et al., 2018a, b; Sharma and Sood, 2019a, b; Sharma et al., 2020). Recently, the coconut based extenders (Waidi et al., 2007; Mollineau et al., 2011), soybean based extenders (Roof et al., 2012; Salmani et al., 2013; Vidal et al., 2013; Chelucci et al., 2015; Narwade et al., 2017; Kakati et al., 2019), plant extract extenders (Zanganeh et al., 2013; Zaenuri et al., 2014) have also been used with good results.

\section{Osmolality, $\mathbf{p H}$ and buffering systems:} Osmotic stress seems to be an important factor in cryopreservation. Goat spermatozoa survive cryopreservation and remain fertile in media composed of a wide range of constituents (Purdy, 2006). A variety Variety of sugars, salts and buffers, could be added in different molar concentrations in the cryopreservation medium, without damaging the spermatozoa. In brief goat spermatozoa prefer hyperosmotic medium for cryopreservation. Salamon and Ritar (1982) observed that the optimal tonicity of a Tris-glucose-citric acid goat sperm medium to be $948 \mathrm{kPa}(540 \mathrm{mOsm})$ whereas, Bowen et al. (1988) reported minimum damage to goat sperms with extender having osmolalities between 425 and 525 mOsm, in comparison to either 325 or $625 \mathrm{mOsm}$.

Significant changes in semen $\mathrm{pH}$ can result in cellular and sub-cellular damage, infertility, or sperm mortality. So, in order to sustain the viability and fertilizing ability of spermatozoa it is essential to maintain a proper environment by controlling the $\mathrm{pH}$ alterations in the cryopreservation media (Purdy, 2006; Gangwar et al., 2016). Generally, buffering solution for goat sperm media should have a $\mathrm{pKa}$ of $7.0(\mathrm{pH}$ range of $6.0-8.0$ ), be water-soluble water soluble and membrane-impermeable membrane impermeable , have minimal interactions with salts, be minimally affected by buffer concentration, temperature and ionic contents on the dissociation of the buffer, and be able to withstand enzymatic and non-enzymatic degradation (Graham et al., 1972). However, the $\mathrm{pH}$ of egg yolk or milk-based goat sperm diluents should normally be between 6.75 and 6.8 (Tuli and Holtz, 1992).

Different theories determining the action of the buffers have been proposed, but it is generally assumed that buffers aid in the cellular dehydration process by creating an osmotic environment thereby increasing the physical stability of the sperm cell plasma membrane and neutralizing acids generated during in vitro storage (Molinia et al., 1994). Tris seems to be the buffer of choice for use with buck sperm, but it is not the case in other species where negative effects of the buffer, such as increased capacitation and acrosome reaction rates and swelling of the apical ridge of the sperm cell have been reported (Molinia et al., 1996).

Sugars: Sugars play an important role in sperm respiration and provide osmotic balance and cryoprotection in diluents. The semen diluents contain a variety of sugars, with a wide range of osmolalities (6-375 mM) (Salamon and Ritar, 1982; Evans and Maxwell, 1987). The choice of sugar to be included in a diluent may be based on the functionality of the chemical. Fructose is a primary substrate for glycolysis in goat seminal plasma, so, it is logical to include this sugar in the medium (Pellicer-Rubio et al., 1997). Similarly, glucose is an excellent substrate in goat sperm metabolism and is essential for providing energy so that the sperm cells can function in a normal physiological manner (Corteel, 1974; Purdy, 2006; Gangwar et al., 2016).

Both fructose and glucose are low-molecular weight low-molecular weight sugars that can pass through the plasma membrane of a sperm. Various effects can be observed when sugars that are not capable of diffusing across a plasma membrane, such as lactose, sucrose, raffinose, trehalose or dextrans (Aboagla 
and Terada, 2003; Kundu et al., 2002; Beltran et al. 2013; Narwade et al., 2017) are added to the diluent. These sugars create an osmotic pressure, inducing cellular dehydration and therefore, a lower incidence of intracellular ice formation. These sugars also interact with the plasma membrane phospholipids, reorganizing the membrane which results in sperm which is able to survive the cryopreservation process (Molinia et al., 1994; Aisen et al., 2002). Unlike the simple sugars glucose and fructose, these disaccharides act primarily as cryoprotectants. Trehalose has also been included in goat sperm cryopreservation extenders. It penetrates the plasma membrane of the spermatozoa and formed form hydrogen bonds with the polar head groups of the phospholipids (Liu et al., 1998; Aboagla and Terada, 2003). The addition of trehalose into the membrane limits the amount of dehydration and consequently the physical damage due to cell volume changes associated with freezing and thawing (Liu et al., 1998). Trehalose also causes an increase in membrane fluidity due to protein and phospholipid reorganization, suppression of the injurious effects of the membrane lipid phase transition (Aboagla and Terada, 2003). In brief, cellular damage is minimized due to less intracellular ice formation leading to increased viability following cryopreservation (Aboagla and Terada, 2003; Yodmingkwan et al., 2016; Narwade et al., 2017).

Cryoprotectants: A cryoprotectant is included in a cryopreservation medium to minimize the physical and chemical stresses resulting from the cooling, freezing and thawing of sperm cells. Cryoprotectants are classified as either penetrating or non-penetrating. A penetrating cryoprotectant is membrane permeable and acts both intra as well as excellularly intra and extracellularly. Penetrating cryoprotectants are solutes, which cause dehydration of spermatozoa due to the osmotically driven flow of water, which varies according to compound. After a short period of time, the cryoprotectant and water equilibrate and result in similar intracellular and extracellular concentrations (Amann, 1999; Sathe and Shipley, 2015). The penetrating cryoprotectants also cause membrane lipid and protein rearrangement, which results in increased membrane fluidity, greater dehydration at lower temperatures and therefore, an increased ability to survive cryopreservation (Holt, 2000). Additionally, penetrating cryoprotectants are solvents that dissolve sugars and salts in the cryopreservation medium (Purdy, 2006; Gangwar et al., 2016).
Many membrane-permeable cryoprotectants (glycerol, dimethyl sulfoxide, ethylene glycol, and propylene glycol), and their combinations, have been tested with buck sperm by various researchers (Tuli and Holtz, 1994; Ritar et al., 1990; Singh et al., 1995; Kundu et al., 2000; Leboeuf et al., 2000; Purdy, 2006; Gangwar et al., 2016; Sharma, 2018; Sharma and Sood, 2019a), but the most frequently used penetrating cryoprotectant is glycerol. The addition of glycerol may be performed in a 1,2 or 3 -step technique at either $37^{\circ} \mathrm{C}$ or $5^{\circ} \mathrm{C}$ (Tuli and Holtz, 1994; Leboeuf et al., 2000; Beltran et al., 2013; Kulaksiz et al., 2013). Glycerol, dimethyl sulfoxide (DMSO) and ethylene glycol are generally used in a range of 1-8\% per cent, but the greatest recovery of sperm post-thawing has been achieved with glycerol (Tuli and Holtz, 1994; Singh et al., 1995; Kundu et al., 2000; Kulaksiz et al., 2013; Narwade et al., 2017; Sharma, 2018; Sharma and Sood, 2019a; Sharma et al., 2020). Combinations of cryoprotectants, such as glycerol and DMSO, have also been tried and yielded synergistic positive results (Kundu et al., 2001).

Non-penetrating cryoprotectant cryoprotectants cannot cross the sperm plasma membrane and therefore, only acts extracellularly (Amann, 1999; Sathe and Shipley, 2015). Therefore, a nonpenetrating cryoprotectant may modify the plasma membrane of a cell, or act as a solute and lower the freezing temperature of the medium (Amann, 1999). The most common non-penetrating cryoprotectants used are egg yolk (2-20\%) (Tuli and Holtz, 1994; Beltran et al., 2013; Gangwar et al., 2016; Sharma, 2018; Sharma et al., 2018b) and non-fat skim milk (10\%) (Purdy, 2006; Kulaksiz et al., 2013; Gangwar et al., 2016). Ferreiral et al. (2014) suggested higher egg yolk extender (10\%) provide better viability to Sannen goat semen cryopreserved at $-196{ }^{\circ} \mathrm{C}$ and seminal plasma removal does not improve the seminal parameters. Similar results were observed by Sharma et al. (2018a) in Gaddi goats and Priyadharsini et al. (2011) in Jakhrana goat semen. Whereas, Beltran et al. (2013) recommended Tris-Citric acid-RaffinoseGlycerol extender supplemented with 5\%per cent egg yolk, $2.5 \%$ per cent goat serum or $30 \mathrm{mg}$ BSA for the cryopreservation of Anglo-Nubian, Boer and Saanen buck semen on basis of sperm motility, percentage of intact acrosome and percent abnormalities at postthawpost thaw.

Apart from above, certain membrane-impermeable membrane impermeable chemicals may be used as

January-June 2020 | Volume 6 | Issue 1 | Page 49 
cryoprotectants. Kundu etal.(2001) demonstrated that amino acids (1-proline, 1 -alanine, glycine or glutamine, $100-150 \mathrm{mM}$ ) could be used as cryoprotectants in goat sperm cryopreservation media with better postthaw results. He also hypothesized the synergistic effect of combination of glycerol, DMSO and dextran (10-2000 kDa) during cryopreservation which is both intracellular and extracellular (Kundu et al., 2002).

\section{Factors affecting semen cryopreservation}

Various factors affecting the sperm cryopreservation viz. species and individuals, sperm collection method, collection season, extender composition, cooling rate, equilibration time, freezing rate and thawing rate (Purdy, 2006; Gangwar et al., 2016).

Species and individuals: Knowledge of sperm biology for the species is essential to maximize postthaw recovery of spermatozoa and consequently fertility (Purdy, 2006). Sperm cryopreservation protocols vary between species due to differences in cell shape and volume as well as organelles size and membrane lipid composition (Holt, 2000; Medeiros et al., 2002). Boar semen is highly cryosensitive, whereas ram, bull, human, rabbit and rooster sperms are cryoresistant (Holt, 2000). In small ruminants, particularly goat, the specific differences with regards to sperm susceptibility to freezing methods, has been observed (Barbas and Mascarenhas, 2009). Also, inter-male or even inter-ejaculates variability has been recognized recognised as a source of variation during the cryopreservation procedure (Soler et al., 2003; Furstoss et al., 2010; Medrano et al., 2010; Ramon et al., 2013). Hence, it is imperative to identify these species differences in spermatozoan sensitivity to cold shock and apply handling protocols to avoid cellular damage during cryopreservation.

Semen extension and concentration: It is essential for a semen sample to be extended properly so that there are sufficient number of sperms for insemination to obtain optimum fertility rates using the least number of inseminations and the lowest number of sperms per insemination (Purdy, 2006; Gangwar et al., 2016). Historically, semen samples in farm animals have been extended by adding specific volumes of extender or by specific spermatozoa concentration. Extension rates of 1:1-1:23 (v/v, semen to extender) have been used successfully (Evans and Maxwell, 1987; Ritar et al., 1990; Sharma, 2018). However, a better method of extension is based on sperm concentration. Successful freezing of sperms and reasonable fertility in goats have been achieved, with samples ranging from 80 to $600 \times 10^{6}$ cells/ml (Mara et al., 2007; Faigl et al., 2012; Jimenez-Rabadan et al., 2013; Gangwar et al., 2016; Sharma, 2018; Sharma et al., 2018a, b; Sharma and Sood, 2019a, b; Sharma et al., 2020).

Equilibration: Equilibration is the total time during which, spermatozoa remain in contact with glycerol before freezing. However, equilibratio $n$ process applies not only to glycerol, but also to the other osmotically active extender components. Therefore, the equilibration process can interact with the type of extender used (buffer and cryoprotectant) and could easily interact with other cryogenic procedures (Vishwanath and Shannon, 2000; Muino et al., 2007). Different equilibration periods ranging from 1 to 5 $h$ with variable post-thaw seminal quality have been used in bucks (Sivaselvam et al., 2000; Sundararaman and Edwin, 2005, 2008; Narwade et al., 2017; Sharma, 2018). Bittencourt (2006) and Ranjan et al. (2015) observed better post-thaw semen quality with equilibration period of $4 \mathrm{hr}$. Contrarily, Baruah et al. (2003) did not observe any significant differences in sperm motility and acrosomal integrity in the semen samples equilibrated for $0.5,1$ and $1.5 \mathrm{~h}$.

Freezing of semen: Diluted buck semen cooled to $4-5{ }^{\circ} \mathrm{C}$ over $1.5-4 \mathrm{~h}$ was then frozen either in pellets or straws (Leboeuf et al., 2000; Mollineau et al., 2011; Gangwar et al., 2016; Sharma, 2018). Freezing of sperm in pellets is rapid and inexpensive, but inventory management is problematic, as the actual semen samples cannot be labelled. Once the semen sample is cooled, semen aliquots of 0.1-0.3 $\mathrm{ml}$ are dispensed into indentations on a block of dry ice (solid carbon dioxide, $-79^{\circ} \mathrm{C}$ ) and frozen for $2-4$ min. The pellets are then plunged into liquid nitrogen for storage (Chemineau et al., 1991; Mollineau et al., 2011). The freezing of sperm in straws is more expensive and laborious than the pellet technique, but each sample can be labeled for accurate inventory management. After extending and cooling the semen samples, the sperms are loaded into 0.25 or $0.5 \mathrm{ml}$ straws, placed on a rack, and frozen in liquid nitrogen vapor, the temperature of which varies by the height above the liquid nitrogen. A styrofoam box containing liquid nitrogen or a programmable freezer that controls the cooling rate had have been successfully used to cryopreserve the goat sperm (Nuti, 2007; Gangwar et al., 2016, Sharma, 2018; 
Sharma et al., 2020). When using a styrofoam box, the rack containing the samples is placed into the liquid nitrogen vapor at a height of $3-4 \mathrm{~cm}$ above the liquid nitrogen for 7-8 $\mathrm{min}$ and the straws are then plunged in liquid nitrogen for storage (Nuti, 2007; Gangwar et al., 2016; Sharma, 2018). Alternatively, Chemineau et al. (1991) reported straw size should determine the freezing height above the liquid nitrogen. He suggested that $0.5 \mathrm{ml}$ straws should be frozen $4 \mathrm{~cm}$ above liquid nitrogen for $5 \mathrm{~min}$, and then, plunged into the liquid nitrogen, while $0.25 \mathrm{ml}$ straws should be placed $16 \mathrm{~cm}$ above the liquid nitrogen for $2 \mathrm{~min}$, lowered to $4 \mathrm{~cm}$ for $3 \mathrm{~min}$, and plunged into the liquid nitrogen for storage. However, researchers (Gravence et al., 1997; Leboeuf et al., 2000; Beltran et al., 2013; Kucuk et al., 2014; Yodmingkwan et al., 2016; Narwade et al., 2017; Sharma, 2018) have used variable freeze height and time combinations $(4-5 \mathrm{~cm}$ above liquid nitrogen for 5-7 $\mathrm{min}$ ) with acceptable results. Programmable freezers are convenient for the freezing of large quantities of semen straws and for controlling the rate of freezing. These freezers may be used to replicate pellet freezing by placing the semen straws in a freezer at $-80{ }^{\circ} \mathrm{C}$ for $7-15 \mathrm{~min}$ and then plunging the semen straws into liquid nitrogen (Blash et al., 2000; Batista et al., 2009). Ritar et al. (1990) observed sperm frozen in pellets to yield superior motility following thawing (39\%) compared to sperm frozen in straws. However, there was no variation in post-thaw motility (PTM) in terms of type of straw used (33\% PTM, $0.25 \mathrm{ml}$; and 34\% PTM, $0.5 \mathrm{ml}$ straw). Differences in PTM, viability and fertility may be attributed to the different cooling rates produced by the pellet and straw techniques (Ritar, 1993).

Thawing of goat semen: The thawing Thawing of semen samples is determined by the method used to freeze the sperm. Sperm pellets of goat semen are thawed in a dry test tube at $37^{\circ} \mathrm{C}$ while the thawing of goat semen straws may be performed using various methods (Evans and Maxwell, 1987). Traditionally, a straw is thawed by placing it in a $37^{\circ} \mathrm{C}$ water bath for 12-30s (Deka and Rao, 1987; Sariozkan et al., 2010; Narwade et al., 2017; Sharma, 2018; Sharma et al., 2018a, b; Sharma and Sood, 2019a, b). This method is superior to a slow thawing technique (36.1 versus $18.9 \%$ motility), where the semen straw is placed in a $5{ }^{\circ} \mathrm{C} \mathrm{C}$ water bath for $2 \mathrm{~min}$ (Deka and Rao, 1987). Increasing the thawing temperature to $70{ }^{\circ} \mathrm{C}$ and thawing the semen straw for only $7 \mathrm{~s}$ resulted in significantly higher progressive motility (36.9\%) and January-June 2020 | Volume 6 | Issue 1 | Page 51 plasma membrane integrity (39.8\%) compared to thawing straws at $37^{\circ} \mathrm{C}$ for $2 \mathrm{~min}(31.5 \%, 33.7 \%$, progressive motility and plasma membrane integrity, respectively), or $40^{\circ} \mathrm{C}$ for $20 \mathrm{~s}(32.4,33.5 \%$, progressive motility and plasma membrane integrity, respectively) $(\mathrm{P}<0.05$, Tuli et al., 1991). Similarly, Penitente-Filho et al. (2014) observed improved sperm membrane functional integrity $(\mathrm{P}<0.05)$ by thawing the straws at $60^{\circ} \mathrm{C}$ for $7 \mathrm{~s}$. Ramchandran et al. (2015) used thawing rates at $40^{\circ} \mathrm{C}$ for $45 \mathrm{~s}$ with good post thaw results (31.47\%, progressive motility) in Jamunapari bucks.

\section{Conclusion and Recommendations}

Sperm cryopreservation is an intricate process leading to multidimensional damages to the sperm, interns reducing their fertilizing capacity. Species-specific Species specific variations in plasma membrane and other components occur in bucks posing huge problems with regards to cryopreservation. All the factors responsible for affecting the cryopreservation results should be given due importance. Keeping interbreed variations in mind, researchers should now focus on standardization of extender and its different components for a particular breed.

\section{Acknowledgements}

Authors acknowledge the financial assistance by Department of Dairy and Fisheries, GOI AdhocMisc 2127-37 project for carrying out this work.

\section{Authors Contribution}

All authors worked in collaboration for writing the review.

\section{Conflict of interest}

The authors have declared no conflict of interest.

\section{References}

Aboagla, E.M.E. and Terada, T., 2003. Trehaloseenhanced fluidity of the goat sperm membrane and its protection during freezing. Biol. Rep. 69: 1245-1250. https://doi.org/10.1095/ biolreprod.103.017889

Aisen, E.G., Medina, V.H. and Venturino, A., 2002. Cryopreservation and post-thawed fertility of ram semen frozen in different trehalose concentrations. Theriogenol. 57: 
1801-1808. https://doi.org/10.1016/S0093691X(02)00653-2

Amann, R.P., 1999. Cryopreservation of sperm. In: Knobil E, Neill JD. (Eds.), Encyclopedia of reproduction. academic press, Burlington, MA, pp. 773-783.

Andrabi, S. and Maxwell, W., 2007. A review on reproductive biotechnologies for conservation of endangered mammalian species. Anim. Reprod. Sci. 99: 223-243. https://doi.org/10.1016/j. anireprosci.2006.07.002

Azeredo, G.A., Esper, C.R. and Resende, K.T., 2001. Evaluation of plasma membrane integrity of frozen-thawed goat spermatozoa with or without seminal plasma. Small Rumin. Res. 41: 257- 263. https://doi.org/10.1016/S09214488(01)00189-4

Bailey, J.L., Bilaodeau, J.F. and Cormier, N., 2000. Semen cryopreservation in domestic animals: a damaging capacitating phenomenon. J. Andro. 20: $1-7$.

Barbas, J.P. and Mascarenhas, R.D., 2009. Cryopreservation of domestic animal sperm cells. Cell Tissue Bank 10: 49-62. https://doi. org/10.1007/s10561-008-9081-4

Barker, C.A., 1957. Some aspects of artificial insemination in swine and goats. Proc. $10^{\text {th }}$ Ann. Conv. Nat. Assoc. Artif. Breed., Toronto, pp. 127-132.

Baruah, C.K., Biswas, R.K., Deka, B.C. and Borgohain, B.N., 2003. Effect of glycerol equilibration periods on quality of frozen semen in Beetal x Assam Local crossbred goats. Ind. Vet. J. 80: 763-765.

Batista, M., Nino, T., Alamo, D., Castro, N., Santana, M. Gonzalez, F., Cabrera, F. and Gracia, A., 2009. Successful artificial insemination using semen frozen and stored by an ultrafreezer in the Majorera goat breed. Theriogenol. 71: 1307- 1315. https://doi.org/10.1016/j. theriogenology.2008.12.024

Beltran, M.A.G., Eufrocina, P.A., Edwin, C.A., Emilo, M.C., Flocerfida, P.A. and Libertado, C.C., 2013. Optimized extenders for cryopreservation of buck semen for artificial insemination. Philipp. J. Vet. Anim. Sci. 39(1): $1-10$.

Bittencourt, R.F., Filho, R.A.L., Alves, S.G.G., Biscardi, C.E., Vasconcelos, M.F. and Oba, E., 2006. The effect of equilibration time on the quality of cryopreserved goat semen. Rev. Bras.
Sau. Prod. Anoph. 7: 27-37.

Blash, S., Melican, D. and Gavin, W., 2000. Cryopreservation of epididymal sperm obtained at necropsy from goats. Theriogenol. 54: 899905.

Bowen, J.A., Fonda, E.S. and Kooyman, D.L., 1988. Ultrastructural study of goat spermatozoa frozen at different diluent osmolalities. Proc. W. Section, Am. Soc. Anim. Sci. J. Anim. Sci. 39: 312-315.

Carrier, F.C., Gargouri, Y., Moreau, H., Ransac, S., Rogalska, E. And Verger, R., 1994. Gastric Lipase: Cellular, biochemical and kinetics aspects, pp. 181-205. In: Lipases-Their structure, Biochemistry and Application (P. Wooley and S.B. Petersen, Eds.) Cambridge University Press. Celeghini, E.C.C., Paes, R., de Arruda, Cesar, A.F., de Andrade, Nascimento, J., Raphael, C.F. and Rodrigues, P.H.M., 2008. Effects that bovine sperm cryopreservation using two different extendershasonspermmembranesandchromatin. Anim. Reprod. Sci. 104: 119-131. https://doi. org/10.1016/j.anireprosci.2007.02.001

Chelucci, S., Pasciu, V., Succu, S., Addis, D., Leoni, G.G.,Manca,M.E.,Naitana,S.and Berlinguer,F., 2015. Soybean lecithin-based extender preserves spermatozoa membrane integrity and fertilizing potential during goat semen cryopreservation. Theriogenol. 83: 1064-1074. https://doi. org/10.1016/j.theriogenology.2014.12.012

Chemineau, P., Cagnie, Y., Guerin, Y., Orgeur, P. and Vallet, J.C., 1991. Training manual on artificial insemination in sheep and goats. FAO reproduction and health paper. Food Agric. Organ. U. N., pp. 115-161.

Corteel, J.M., 1974. Viability of goat spermatozoa deep frozen with or without seminal plasma: glucose effect. Ann. Anim. Biol. Biochem. Biophys. 14: 741-745. https://doi.org/10.1051/ rnd:19740502

Curry, M.R., 2007. Cryopreservation of mammalian semen. In: Day J.G., Stacey G.N. (eds) Cryopreservation of freeze-drying protocols. Methods Mol. Biol., Humana Press. vol 368. https://doi.org/10.1007/978-1-59745-3622_21

Deka, B.B. and Rao, A.R., 1987. Effect of extenders and thawing methods on post-thawing preservation of goat semen. Ind. Vet. J. 64: 591594.

Evans, G. and Maxwell, W.M.C., 1987. Frozen storage of semen. Salamon's Artif. Insem. Sheep 
Goats. Butterworths, Wellington, pp. 122-141.

Faigl, V., Vass, N., Jávor, A., Kulcsár, M., Solti, L., Amiridis, G.S. and Cseh, S., 2012. Artificial insemination of small ruminants. A review. Acta Vet. Hung. 60 (1): 115-129. https://doi. org/10.1556/AVet.2012.010

Ferreiral, V.S., Mello, M.R.B., da Fonseca, C.E.M., Dias, A.C.F., Cardoso, J.M., Silva, R.B. and Martins, W.P., 2014. Effect of seminal plasma and egg yolk concentration on freezability of goat semen. Rev. Bras. Zool. 43: 513-518. https://doi. org/10.1590/S1516-35982014001000001

Furstoss, V., Borderes, F., Forgerit, Y. and Guillouet, P., 2010. The value of the percentage of motile sperm in predicting a significant portion of the fertility variation of frozen-thawed buck semen. Theriogenol. 74(7): 1197-206. https://doi. org/10.1016/j.theriogenology.2010.05.022

Gangwar, C., Kharche, S.D., Kumar, S. and Jindal, S.K., 2016. Cryopreservation of goat semen: Status and prospects. India. J. Small Rumin. 22: 1-10. https://doi.org/10.5958/09739718.2016.00005.2

Gomes, P.L.N.S., Lipinski, L.C. and Pereira, R.J.T.A., 2009. Assessment of equilibration time in the freezing of goat semen. Ciência. Anim. Brasileira. 10: 808-813.

Graham, E.F., Crabo, B.G. and Brown, K.I., 1972. Effect of some zwitter ion buffers on the freezing and storage of spermatozoa in bulls. J. Dairy Sci. 55: 372-378. https://doi.org/10.3168/jds. S0022-0302(72)85499-7

Gravance, C.G.C. White, Robertson, K.R., Champion, Z.J. and Casey, P.J., 1997. The effects of cryopreservation on the morphometric dimensions of caprine sperm heads. Anim. Reprod. Sci. 49: 37-43. https://doi.org/10.1016/ S0378-4320(97)00053-5

Hiemstra S.J., Van der Linde, T. and Woelders, H., 2005. The potential of cryopreservation and reproductive technologies for animal genetic resources conservation strategies. The role of biotechnology. Villa Giuliana, Turin, Italy. FAO. Rome, Italy.

Holt, W.V., 2000. Basic aspects of frozen storage of semen. Anim. Reprod. Sci. 62: 3-22. https://doi. org/10.1016/S0378-4320(00)00152-4

Iritani, A. and Nishikawa. 1963. Studies on the eggcoagulating enzyme in goat semen, IV. On the position of yolk consitituents attacked by the coagulating enzyme. Japan J. Anim. Reprod. 8: 113-117.https://doi.org/10.1262/jrd1955.8.118

Isachenko, E., 2003. Vitrification of mammalian spermatozoa in the absence of cryoprotectants: from past practical difficulties to present success. Reprod. Biomed. Online. 6(2): 191-200. https:// doi.org/10.1016/S1472-6483(10)61710-5

Jimenez-Rabadan, P., Ramon, M., Garcia-Alvarez, O., Maroto-Morales, A., Alvaro-Garcia, P.J., Perez-Guzman, M.D., Fernandez-Santos, M.R., Julian Garde, J. and Soler, A.J., 2013. Improved cryopreservation protocol for Blanca-Celtiberica buck semen collected by electroejaculation. Cryobiol. 67: 251- 257. https://doi. org/10.1016/j.cryobiol.2013.08.002

Kakati, U., Sinha, S., Deka, B., Biswas, R., Baruti, M., Nahardeka, N. and Borah, R., 2019. Effect of Soybean lecithin based extended and Ovixcell on quality of frozen semen in Beetal, Sirohi and Assam hill goat. Int. J. Livest. Res. 9(1): 95-110. https://doi.org/10.5455/ijlr.20180509033715

Konyali, C., Tomas, C., Blanch, E., Gomez, E.A., Graham, J.K. and Moce, E.. 2013. Optimizing conditions for treating goat semen with cholesterol-loaded cyclodextrins prior to freezing to improve cryosurvival. Cryobiol. 67: 124-131. https://doi.org/10.1016/j.cryobiol.2013.06.001

Küçük, N., Aksoy, M., Uçan, U., Ahmad, E., Naseer, Z., Ceylan, A. and Serin, I., 2014. Comparison of two different cryopreservation protocols for freezing goat semen. Cryobiol. 68(3): 327-331. https://doi.org/10.1016/j.cryobiol.2014.04.009

Kulaksiz, R., Ari, U.C., Daskin, A. and Üner, A.G., 2013. The effect of different glycerol concentrations on freezability of semen from Angora, Kilis and Saanen goats. Slovak. J. Anim. Sci. 46: 39-44.

Kundu, C.N., Chakrabortym J., Duttam P., Bhattacharyyam D., Ghoshm A. and Majumdarm G.C., 2002. Effect of dextrans on cryopreservation of goat cauda epididymal spermatozoa using a chemically defined medium. Reprod. 123: 907-913. https://doi.org/10.1530/ reprod/123.6.907

Kundu, C.N., Chakraborty, J., Dutta, P., Bhattacharyya, D., Ghosh, A. and Majumdar, G.C., 2000. Development of a simple sperm cryopreservation model using a chemically defined medium and goat cauda epididymal spermatozoa. Cryobiol. 40: 117-125. https:// doi.org/10.1006/cryo.2000.2230

Kundu, C.N., Das, K. and Majumder, G.C., 2001. 
Effect of amino acids on goat cauda epididymal sperm cryopreservation using a chemically defined model system. Cryobiol. 41: 21-27. https://doi.org/10.1006/cryo.2001.2296

Leboeuf, B., Restall, B. and Salamon, S., 2000. Production and storage of goat semen for artificial insemination. Anim. Reprod. Sci. 62: 113-141. https://doi.org/10.1016/S03784320(00)00156-1

Liu, Z., Foote R.H. and Brockett, C.C., 1998. Survival of bull sperm frozen at different rates in media varying in osmolarity. Cryobiol. 37: 219230. https://doi.org/10.1006/cryo.1998.2117

Mara, L., Dattena, M., Pilichi, S., Sanna, D., Branca, A. and Cappai, P., 2007. Effect of different diluents on goat semen fertility. Anim. Reprod. Sci. 102(1-2): 152-157. https://doi. org/10.1016/j.anireprosci.2007.02.007

Martin, G., Sabido, O., Durand, P. and Levy, R., 2004. Cryopreservation induces an apoptosis-Like mechanism in bull sperm. Biol. Reprod. 71: 28-37. https://doi.org/10.1095/ biolreprod.103.024281

Medeiros, C.M., Forell, F., Oliveira, A.T. and Rodrigues, J.L., 2002. Current status of sperm cryopreservation: why isn't it better? Theriogenol. 57: 327-344. https://doi.org/10.1016/S0093691X(01)00674-4

Medrano, A., Terrazas, A. and Soto, R., 2010. Principles and perspectives for the conservation of goat buck spermatozoa. Small Rumin. Res. 89: 140-143. https://doi.org/10.1016/j. smallrumres.2009.12.036

Mishra, B., Alam, M.G.S., Khandokar, M.A.M.Y., Mazumder, S. and Munsi, M.N., 2010. Qualities of goat semen in Tris-Citrate-Glucose extender containing glutathione. Bangla. Vet. 27: 46-55. https://doi.org/10.3329/bvet.v27i2.7554

Molinia, F.C., Evans,G. and Maxwell, W.M.C., 1996. Fertility of ram spermatozoa pelletfrozen in zwitterion-buffered diluents. Repror. Nutr. Dev. 36: 21-29. https://doi.org/10.1051/ rnd:19960102

Molinia, F.C., Evans,G., Caseres, P.I. and Maxwell, W.M.C., 1994. Effect of monosaccharides and disaccharides in Tris-based diluents on motility, acrosome integrity and fertility of pellet frozen ram spermatozoa. Anim. Reprod. Sci. 36: 113-122. https://doi.org/10.1016/03784320(94)90058-2

Mollineau, W.M., Adogwa, A.O. and Garcia, G.W.,
2011. Liquid and frozen storage of Agouti (Dasyprocta leporina) semen extended with UHT milk, unpasteurized coconut water, and pasteurized coconut water. Vet. Med. Int. 1-5. https://doi.org/10.4061/2011/702635

Muiño, R., Fernandez, M. and Peña, A., 2007. Postthaw survival and longevity of bull spermatozoa frozen with an egg yolk-based or two egg yolk-free extenders after an equilibration period of 18h. Reprod. Dom. Anim. 42(3): 305-311. https://doi.org/10.1111/j.14390531.2006.00784.x

Munyai, P.H., 2012. Cryopreservation of South African indigenous ram semen. MSc thesis, University of the Free State, South Africa.

Narwade, B.M., Mohanty, T.K., Bhakat, M. and Rahim, A., 2017. Goat semen cryopreservation using egg yolk and soya based extenders containing trehalose. India. J. Anim. Sci. 87(7): 851-855.

Nuti, I., 2007. Techniques of artificial insemination in goats. In: Youngquist, R.S. and Threlfall, W.R (eds) current therapy in large animal theriogenology. (2 ${ }^{\text {nd }}$ Ed.) Sounders-Elsevier, St. Louis, MO. pp. 529-534. https://doi. org/10.1016/B978-072169323-1.50071-4

Parkinson, T., 2009. Artificial insemination of ewes. In: Noakes, D.E., Parkinson, T.J. and England, G.C.W. (eds) Veterinary Reproduction and Obstetrics. (9 ${ }^{\text {th }}$ Ed.) Saunders- Elsevier, London, UK. pp. 765-808.

Parks, J.E. and Graham, J.K., 1992. Effects of cryopreservation procedures on sperm membranes. Theriogenol. 38: 209-222. https:// doi.org/10.1016/0093-691X(92)90231-F

Pellicer-Rubio, M.T and Combarnous, Y., 1998. Deterioration of goat spermatozoa in skimmed milk-based extenders as a result of oleic acid released by the bulbourethral lipase BUSgp60. J. Reprod. Fert. 112: 95-105. https://doi. org/10.1530/jrf.0.1120095

Pellicer-Rubio,M.T., Magallon, T. and Combarnous, Y., 1997. Deterioration of goat sperm viability in milk extenders is due to a bulbourethral 60-kilodaltonglycoprotein with triglyceride lipase activity. Biol. Reprod. 57: 1023-1031. https://doi.org/10.1095/biolreprod57.5.1023

Penitente-Filho, J.M., Oliveira, F.A., Jimenez, C.R., Carrascal, E., Dias, J.C.O., Oliveira, G.D., Silveira, R.G., Silviera, C.O. and Torres, C.A.A., 2014. Association of vitamin $\mathrm{E}$ with 
rapid thawing on goat semen. Sci. World J. 1-5.

https://doi.org/10.1155/2014/964172

Priyadharsini, R., Jindal, S.K., Sharma, D., Ramachandran, N., Kharche, S.D. and Goel, A.K., 2011. Effect of different egg yolk level on the cryopreservation capability of Jakhrana goat semen. J. Anim. Sci. Adv. 1(1): 28-37.

Purdy, P.H., 2006. A review on goat sperm cryopreservation. Small Rumin. Res. 63: 215-225. https://doi.org/10.1016/j. smallrumres.2005.02.015

Ramachandran, N., Yadav, S., Sikarwar, A.K.S., Saraswat, S., Ranjan, R. and Jindal, S.K., 2015. Effect of equilibration periods on post-thaw semen quality of Jamunapari bucks. Indian J. Small Rumin. 21(2): 234-237. https://doi. org/10.5958/0973-9718.2015.00053.7

Ramón, M., Soler, A.J., Ortiz, J.A., García-Alvarez, O., Maroto-Morales, A., Roldan, E.R.S. and Garde, J.J., 2013. Sperm population structure and male fertility: an intraspecific study of sperm design and velocity in red deer. Biol. Reprod. 89: 110. https://doi.org/10.1095/ biolreprod.113.112110

Ranjan, R., Goel, A.K., Ramchandran, N., Kharche, S.D. and Jindal, S.K., 2015. Effect of egg yolk levels and equilibration periods on freezability of Jamunapari buck semen. Indian J. Small Rumin. 21(1): 32-36. https://doi.org/10.5958/09739718.2015.00027.6

Ritar, A.J., Ball, P.D. and May, P.J.O., 1990. Artificial insemination of Cashmere goats: effects on fertility and fecundity of intravaginal treatment, method and time of insemination, semen freezing process, number of motile spermatozoa and age of females. Reprod. Fert. Dev. 2: 377384. https://doi.org/10.1071/RD9900377

Ritar, A.J., 1993. Control of ovulation, storage of semen, and artificial insemination of fibreproducing goats in Australia: a review. Aust. J. Exp. Agri. 33: 807-820.

Roof, D.J., Bowley, S., Price, L.L. and Matsas, D.J., 2012. Comparison of two commercial extenders for cryopreservation of goat semen without sperm washing. Theriogenol. 77: 412-420. https://doi. org/10.1016/j.theriogenology.2011.08.015

Salamon,S.and Maxwell,W.M.,2000.Storage of ram semen. Anim. Reprod. Sci. 62: 77-111. https:// doi.org/10.1016/S0378-4320(00)00155-X

Salamon, S. and Ritar, A.J., 1982. Deep freezing of Angora goat semen: effects of diluent composition and method and rate of dilution on survival of spermatozoa. Aust. J. Biol. Sci. 35: 295-303. https://doi.org/10.1071/BI9820295

Salmani, H., Nabi, M.M., Dodaran, H.V., Rehman, M.B., Sangcheshmeh, M.A., Shakeri, M., Towhidi, A., Shahneh, A.Z. and Zandi, M., 2013. Effect of glutathione in soybean lecithin based semen extender on goat semen quality after freeze-thawing. Small Rumin. Res. 112: 123-127. https://doi.org/10.1016/j. smallrumres.2012.12.015

Sariözkan, S., Bucak, M.N., Tuncer, P.B., Taşdemir, U., Kinet, H. and Ulutas, P.A., 2010. Effects of different extenders and centrifugation/washing on post thaw microscopic-oxidative stress parameters and fertilizing ability of Angora buck sperm. Theriogenol. 73: 316-323. https://doi. org/10.1016/j.theriogenology.2009.09.015

Sathe, S. and Shipley. C.F., 2015. Cryopreservation of semen. In: Richard M Hooper John Bovine reproduction. $1^{\text {st }}$ ed, Wiley and Sons, Inc.pp. 662670. https://doi.org/10.1002/9781118833971. ch71

Sawyer, D.E. and Brown, D.B., 1995. The use on an in vitro sperm activation assay to detect chemically induced damage of human sperm nuclei. Reprod. Toxicol. 9: 351-357. https://doi. org/10.1016/0890-6238(95)00021-2

Sharma, A., 2018. Investigation on follicular dynamics and semen cryopreservation in goats $\mathrm{PhD}$ thesis Cskhpkv Palampur, Himachal Pradesh, India.

Sharma, A., Sood, P. and Dogra, P., 2018a. Seminal plasma removal improves cryopreserved semen quality in Gaddi bucks. Indian J. Anim. Reprod. 39 (2): 25-28.

Sharma, A., Sood, P. and Dogra, P., 2018b. Effect of varying concentrations of egg yolk in cryopreservation of Gaddi goat semen. Proceeding, $30^{\text {th }}$ World Buiatrics Congress w.e.f $28^{\text {th }}$ Aug to $2^{\text {nd }}$ Sep. 2018 at Sapporo, Japan pp. 348-349.

Sharma, A. and Sood, P., 2019a. Cryopreservation and fertility of frozen thawed Chegu goat semen. Indian J. Anim. Res. 53(11): 1414-1419. https:// doi.org/10.18805/ijar.B-3696

Sharma, A. and Sood, P., 2019b. Effect of varing concentration of glycerol in cryopreservation of Gaddi goat semen. Proceeding, ISSGPU National Seminar on "Current Scenario and future strategies for augmenting productivity 
of small ruminants" w.e.f $14^{\text {th }}-16^{\text {th }}$ Feb. 2019 at Bihar Anim. Sci. Univ., Patna, pp. 75.

Sharma, A., Sood, P. and Chaudhary, J.K., 2020. Correlation of climatic conditions with seminal quality parameters in Gaddi and Chegu buck semen. Asi.J. Anim. Vet. Adv. 15:32-37. https:// doi.org/10.3923/ajava.2020.32.37

Shipley, C.F.B., Brian, C., Buckrell, B.C., Mylne, M.J.A. and Pollard, J., 2007. Artificial insemination and embryo transfer in sheep. In: Youngquist, R.S. and Threlfall, W.R. (eds). Curr. Therapy Large Anim. Theriogenol. $\left(2^{\text {nd }} \mathrm{Ed}\right.$.) Saunders-Elsevier, St. Louis, MO. pp. 629-641. https://doi.org/10.1016/B978-0721693231.50089-1

Singh, M., Sinha, A.K. and Singh, B.K., 1995.Effect of cryoprotectants on certain seminal attributes and on the fertility of buck spermatozoa. Theriogenol. 43: 1047-1053. https://doi. org/10.1016/0093-691X(95)00068-J

Sivaselvam, S.N., Edwin, M.J., Subramanian, A., Rahumathulla, P.S. and Natarajan, N., 2000. Cryopreservation of goat semen: Standardization of freezing protocol. Cheiron. 29: 73-76.

Smith, A.U. and Polge, C., 1950. Survival of spermatozoa at low temperatures. Nature, 166: 668-669. https://doi. org/10.1038/166668a0

Soler, C., de Monserrat, J.J., Gutierrez, R., Nunez, J., , Nunez, M., Sancho, M., Perez-Sanchez, F. and Cooper, T.G., 2003. Use of the SpermClass Analyser for objective assessment of human sperm morphology. Int. J. Andron. 26: 262-270. https://doi.org/10.1046/j.13652605.2003.00422.x

Sundararaman, M.N. and Edwin, M.J., 2005. Evaluation of sperm motion characteristics of pre-freeze and post-thaw goat spermatozoa on computer assisted semen analysis (CASA). Indian J. Small Rumin. 11: 92-95.

Sundararaman, M.N. and Edwin, M.J., 2008. Changes in motility characteristics of goat spermatozoa during glycerol-equilibration and the relevance to cryopreservation. Asian J. Cell Biol. 3: 22-33. https://doi.org/10.3923/ ajcb.2008.22.33

Tabarez,A.,Garcia,W.and Palomo,M.J.,2017.Effect of the type of egg yolk, removal of seminal plasma and donor age on buck sperm cryopreservation. Small Rumin. Res. 149: 91-98. https://doi. org/10.1016/j.smallrumres.2017.01.007
Tuli, R.K. and Holtz, W., 1992. The effect of zwitterions buffers on the freezability of Boer goat semen. Theriogenol. 37: 947-951. https:// doi.org/10.1016/0093-691X(92)90056-W

Tuli, R.K. and Holtz, W., 1994. Effect of glycerolization procedure and removal of seminal plasma on post-thaw survival and GOT-release from Boer goat spermatozoa. Theriogenol. 42: 547-555. https://doi.org/10.1016/0093691X(94)90692-C

Tuli,R.K., Schimidt-Baulain, R. and Holtz,W.,1991. Influence of thawing temperature on viability and release of glutamic oxaloacetic transaminase in frozen semen from Boer goats. Anim. Reprod. Sci. 25: 125-131. https://doi.org/10.1016/03784320(91)90037-Z

Upreti, G.C., Hall, E.L., Koppens, D., Oliver, J.E. and Vishwanath, R., 1999. Studies on the measurement of phospholipase A2 (PLA2) and PLA2 inhibitor activities in ram semen. Anim. Reprod. Sci. 56: 107-121. https://doi. org/10.1016/S0378-4320(99)00033-0

Vidal, A.H., Batista, A.M., Cordeiro, E., Silva, B., Gomes, W.A., Pelinica, M.A., Silva, S.V., Medalena, M. and Guerra, P., 2013. Soybean lecithin-based extender as an alternative for goat sperm cryopreservation. Small Rumin. Res. 109: 47-51. https://doi.org/10.1016/j. smalliumres.2012.07.022

Vishwanath, R. and Shannon, P., 2000. Storage of bovine semen in liquid and frozen state. Anim. Reprod. Sci. 62(1-3): 23-53. https://doi. org/10.1016/S0378-4320(00)00153-6

Waidi, F.S., Matthew, O.O. and Matthew, O.A., 2007. Coconut milk-Citrate as extender for WAD buck spermatozoa at room temperature. Biokemistri. 19(2): 65-73. www.bioline.org.br/ request/bk0711.

Watson, P.F. and Holt, W.V., 2001. Organisational issues concerning the establishment of genetic resource bank, In: Watson, P.F. and Holt, W.V. (eds.), Cryobanking the genetic resource. Wildlife conservation the future? Taylor and Francis, London, pp. 86-112.

Yildiz, C., Ottaviani, P., Law, N., Ayearst, R., Liu, L. and Mckerlie, C., 2007. Effects of cryopreservation on sperm quality, nuclear DNA integrity, in vitro fertilization, and in vitro embryo development in the mouse. Reprod. 133: 585595. https://doi.org/10.1530/REP-06-0256 Yodmingkwan, P., Guntaprom, S., Jaksamrit, J. and 
Lertchunhakiat, K., 2016. Effects of extenders on fresh and freezing of Boer goat. Agric. Agric. Sci. Proc. 11: 125-130. https://doi.org/10.1016/j. aaspro.2016.12.021

Zaenuri, L.A., Susilawati, T., Wahyuningsih, S. and Sumitro, S.B., 2014. Effects of Additional Crude Extract of Fig Fruit (Ficus carica L) into Tris Egg Yolk Based Extender on Quality of Buck Semen.
J. Biol. Agric. Healthc. 4(9): 21-27.

Zanganeh,Z.,Zhandi,M.,Zare-Shahneh,A., Najafi, A., Nabi, M.M. and Sangcheshmeh, M.A., 2013. Does rosemary aqueous extract improve buck semen cryopreservation? Small Rumin. Res. 114: 120-125. https://doi.org/10.1016/j. smallrumres.2013.05.015 